\title{
Prevalence of Periimplant Diseases
}

\author{
Giovanni E. Salvi, Prof Dr med dent, ${ }^{*}$ Raluca Cosgarea, PD, Dr med dent, †† and Anton Sculean, Prof Dr med dent, MS§
}

$\mathrm{P}$ eriimplant diseases have been defined as (1) development of periimplant mucosal inflammation without loss of supporting bone (ie, periimplant mucositis) and (2) presence of periimplant mucosal inflammation with additional loss of supporting bone (ie, periimplantitis). ${ }^{1}$ As with the onset of gingivitis and periodontitis, the formation of microbial biofilms on dental implants has been documented to be involved in the development of periimplant mucositis ${ }^{2}$ and periimplantitis. ${ }^{3}$ In subjects diagnosed with moderate to severe periimplantitis, the onset of the disease was shown to occur within 3 years after implant loading and to display a nonlinear accelerating pattern over 9 years. ${ }^{4}$

Furthermore, iatrogenic factors such as poor prosthetic implant positioning, excess cement ${ }^{5}$ and lack of cleansability of the implant-supported restoration ${ }^{6}$ may contribute as plaqueretentive factors to the onset and progression of periimplant diseases.

The aim of the present review was to summarize the evidence on the prevalence of periimplant diseases.

*Vice Chairman and Graduate Program Director, Departmemt of Periodontology, University of Bern, School of Dental Medicine, Bern, Switzerland.

†Assistant Professor, Department of Periodontology, Philipps University Marburg, Marburg, Germany.

†Assistant Professor, Department of Prosthetic Dentistry, University luliu Hatieganu, Cluj-Napoca, Romania. §Chairman, Department of Periodontology, University of Bern, School of Dental Medicine, Bern, Switzerland.

Reprint requests and correspondence to: Giovanni E. Salvi, Prof Dr med dent, Department of Periodontology, University of Bern, School of Dental Medicine,

Freiburgstrasse 7, CH-3010 Bern, Switzerland,

Phone: + 413163235 51, Fax: + 41316324915

E-mail: giovanni.salvi@zmk.unibe.ch

ISSN 1056-6163/19/02802-100

Implant Dentistry

Volume 28 - Number 2

Copyright (C) 2019 Wolters Kluwer Health, Inc. All rights

reserved.

DOI: 10.1097/ID.0000000000000872
Purpose: To report the prevalence of periimplant diseases (ie, periimplant mucositis and periimplantitis).

Material and Methods: A literature search was performed in MEDLINE through PubMed database of the US National Library of Medicine for articles published until March 2018 using Medical Subject Heading (MeSH) search terms complemented by free terms and in different combinations.

Results: A wide range of prevalences of periimplant diseases has been reported in the literature. Subject-based estimated weighted mean prevalences and ranges were reported to amount to $43 \%$ (range:

\section{Materials and Methods}

A literature search was performed in MEDLINE through PubMed database of the US National Library of Medicine for articles published until March 2018 using Medical Subject Heading (MeSH) search terms complemented by free terms and in different combinations. To be included, articles had to be written in the English language and be published in an international peer-reviewed journal.

Abstracts, narrative reviews, studies reporting on early complications before implant loading, and studies with insufficient/unclear informations on clinical and/or radiographic parameters not allowing a case definition of periimplant mucositis and periimplantitis were excluded.

\section{Prevalence of Periimplant Diseases}

The prevalence of periimplant diseases has recently been reported to
19\%-65\%) for periimplant mucositis and to $22 \%$ (range: $1 \%-47 \%$ ) for periimplantitis.

Conclusion: Differences in case definitions impact on extent and severity of periimplant diseases and make comparisons among studies difficult. Convenience samples rather than randomly selected population samples are often analyzed to estimate prevalence of periimplant diseases. More recent studies report implant- and subject-based prevalences of periimplant diseases. (Implant Dent 2019;28:100-102)

Key Words: dental, implant, periimplant infection, epidemiology, periimplantitis, periimplant mucositis

represent a controversial issue. ${ }^{7}$ Subject-based estimated weighted mean prevalences and ranges for periimplant mucositis and periimplantitis were reported in a systematic review with meta-analysis. ${ }^{8}$ The prevalence for periimplant mucositis was reported at $43 \%$ ranging from $19 \%$ to $65 \%$, whereas for periimplantitis, it amounted to $22 \%$ ranging from $1 \%$ to $47 \% .^{8}$ In addition, outcomes from crosssectional studies $^{9-14}$ not included in the systematic review referred to above ${ }^{8}$ reported comparable prevalences for periimplantitis ranging from $12.9 \%$ to $26 \%$.

The prevalence of cases with periimplant mucositis or periimplantitis was recently reported in a case series study with a 21- to 26-year follow-up. ${ }^{15}$ In that study, ${ }^{15} 86$ of 294 subjects who had previously received dental implants ${ }^{16}$ were re-examined on average 
23.3 years later. ${ }^{15}$ The outcomes indicated that $54.7 \%$ of subjects were diagnosed with periimplant mucositis and $22.1 \%$ with periimplantitis, respectively. ${ }^{15}$ Collectively, these results indicate a wide range in the prevalence of periimplant diseases making it difficult to estimate the magnitude of the disease on a universal scale.

\section{Factors Affecting the Prevalence of Periimplant Diseases}

The lack of consensus on case definitions for periimplant diseases represents one of the major methodological discrepancies in epidemiological studies. ${ }^{17,18}$

In cases with baseline radiographs, incidence of periimplantitis was defined as the presence of clinical inflammation and a crestal bone loss of 1 to $1.5 \mathrm{~mm}^{17}$ In cases with missing baseline radiographs, however, the presence of clinical inflammation together with crestal bone-level changes of $2 \mathrm{~mm}$ after the remodeling phase was suggested as definition criteria for periimplantitis. ${ }^{17}$ Despite these recommendations for case definitions, different thresholds in the assessment of crestal bone loss and reference time points from which the specified bone loss occurred have been adopted. For example, in the systematic review by Derks and Tomasi, ${ }^{8}$ the study reporting the lowest prevalence of periimplantitis (ie, $1 \%$ ) considered for the case definition a threshold of crestal bone loss of $5 \mathrm{~mm},{ }^{19}$ whereas the study reporting the highest prevalence of periimplantitis (ie, 47\%) applied a threshold for crestal bone loss of $0.4 \mathrm{~mm} .^{20}$

In a retrospective cross-sectional analysis of a randomly selected population of 588 Swedish subjects, periimplantitis was defined as the presence of bleeding on probing (BoP) and/or suppuration and crestal bone loss $>0.5 \mathrm{~mm} .{ }^{21}$ In that study, a $45 \%$ subject-based prevalence for periimplantitis after 9 years of loading was reported. ${ }^{21}$ However, the severity of the disease decreased to $14.5 \%$ of subjects exhibiting moderate to severe periimplantitis when the threshold for bone loss was $>2 \mathrm{~mm}^{21}$

The fact that, in several studies, only implant-based data were reported and subject-based outcomes were lacking was emphasized in a systematic review on the quality of studies reporting prevalence, incidence, and risk factors for periimplant diseases. ${ }^{18}$ The consensus report of the 8th European Workshop on Periodontology (EWP) considered the prevalence of subjectand not implant-based periimplant diseases to be the outcome of interest emphasizing that research assessing the prevalence of periimplant diseases should focus on subject-level analyses. ${ }^{17}$ This recommendation from the 8th EWP ${ }^{15}$ is already reflected in several investigations including subjectbased analyses. ${ }^{9-14,21,22}$

The time point of implant loading represents an additional factor influencing the reported percentages of prevalence of periimplantitis. In this context, the consensus report of the 8th EWP recommended the inclusion of implants with a loading time "of sufficient duration" without specification of a predetermined time threshold. ${ }^{17}$ However, based on the fact that chronic inflammatory diseases such as periimplantitis requires time to develop, reports on prevalence based on short follow-up times may yield an underestimation of the disease. In this respect, consistent results on the patient-based prevalence of periimplant mucositis (range: $57 \%$ 64.4\%) and of periimplantitis (range: $13.3 \%-29.7 \%$ ) were reported when a mean function time of at least 5 years and a threshold for crestal bone loss $>2$ mm were considered. ${ }^{13,22}$

An additional important issue observed in several studies reporting on prevalence of periimplant diseases is the fact that their analysis is based on convenience samples from universities or private clinics with a limited sample size rather than on large randomly selected cohorts. ${ }^{16,18}$ This limitation may account for selection bias and influences external validity in terms of true prevalence of periimplant diseases. In fact, few studies reporting on the prevalence of periimplant diseases included both subjects treated in private and university settings ${ }^{12,21,23}$ or analyzed a randomly selected population sample. ${ }^{21}$

Finally, factors such as adherence to supportive maintenance care, implant surface characteristics, and prosthetic aspects have been investigated with respect to their impact on the development of periimplant diseases.

Outcomes from a retrospective clinical study indicated that preexisting periimplant mucositis in subjects not adhering to supportive care was associated with a higher incidence of periimplantitis over a 5-year period. ${ }^{24}$ The results of that study yielded a 5-year incidence of periimplantitis of $18.0 \%$ in subjects with supportive care and of $43.9 \%$ in subjects without, respectively. ${ }^{24}$

In addition, patients with a history of treated moderate to severe periodontitis not complying with regular supportive care displayed significantly higher incidences of implant failures and periimplant bone loss $\geq 3 \mathrm{~mm}$ compared with patients complying with supportive care after an observation period of 10 years. ${ }^{25}$

Evidence for the impact of implant surface roughness on the incidence of periimplant mucositis ${ }^{26}$ and periimplantitis $^{27}$ in humans is limited. Outcomes of a systematic review indicated that periimplant mucositis does not seem to be associated with implant or abutment systems with a specific design or surface roughness. ${ }^{26} \mathrm{Fur}$ thermore, outcomes of a clinical study including 2 different implant systems failed to detect differences in the incidence of periimplantitis as an effect of implant surface and design over a follow-up period of 13 years. ${ }^{27}$

Recently, a cross-sectional radiographic study investigated whether or not emergence angle and profile (ie, convex or concave) of implantsupported restorations were associated with periimplantitis. ${ }^{28}$ Cemented and screw-retained restorations supported by bone-level or tissue-level implants were analyzed. Periimplantitis was defined as the presence of $\mathrm{BoP}$ and/or suppuration, $2 \mathrm{~mm}$ of crestal bone loss after initial remodeling and pocket probing depths $\geq 4 \mathrm{~mm}$. The subject-based prevalence of periimplantitis amounted to $28.9 \%$ for bone-level implants and to $14.8 \%$ for tissue-level implants after a mean follow-up time of 10.9 years. ${ }^{28}$

The highest prevalence of periimplantitis (ie, 37.8\%), however, was observed for bone-level implants supporting restorations with both a convex 
profile and a restoration emergence angle $>30$ degrees. $^{28}$ In contrast to bone-level implants, the prevalence of periimplantitis at tissue-level implants was not affected by either emergence angle or profile. ${ }^{28}$ These findings suggest that overcontoured restorations supported by bone-level implants may impair proper self-performed plaque control thereby increasing the risk of developing periimplant diseases.

\section{Comment and Conclusion}

A wide range of prevalences of periimplant diseases is reported in the literature.

Differences in case definitions impact on extent and severity of periimplant diseases and make comparisons among studies difficult. Convenience samples rather than randomly selected population samples are often analyzed to estimate prevalence of periimplant diseases. More recent studies report prevalence of periimplant diseases both at implant and subject level.

\section{Disclosure}

The authors claim to have no financial interest, either directly or indirectly, in the products or information listed in the article.

\section{Roles/Contributions BY Authors}

G. E. Salvi: literature search and preparation of the manuscript. R. Cosgarea: literature search and preparation of the manuscript. A. Sculean: preparation of the manuscript.

\section{REFERENCES}

1. Lindhe J, Meyle J. Peri-implant diseases: Consensus report of the sixth European Workshop on Periodontology. J Clin Periodon. 2008;35:282-285.

2. Salvi GE, Aglietta M, Eick S, et al. Reversibility of experimental peri-implant mucositis compared with experimental gingivitis in humans. Clin Oral Implants Res. 2012;23:182-190.

3. Lindhe J, Berglundh T, Ericsson I, et al. Experimental breakdown of periimplant and periodontal tissues. A study in the beagle dog. Clin Oral Implants Res. 1992;3:9-16.
4. Derks J, Schaller D, Håkansson J, et al. Peri-implantitis-Onset and pattern of progression. J Clin Periodontol. 2016: 43:383-388.

5. Wilson TG Jr. The positive relationship between excess cement and peri-implant disease: A prospective clinical endoscopic study. J Periodontol. 2009;80: 1388-1392.

6. Serino G, Ström C. Peri-implantitis in partially edentulous patients: Association with inadequate plaque control. Clin Oral Impl Res. 2009;20:169-174.

7. Tarnow DP. Increasing prevalence of peri-implantitis: How will we manage? J Dent Res. 2016;95:7-8.

8. Derks J, Tomasi C. Peri-implant health and disease. A systematic review of current epidemiology. J Clin Periodontol. 2015;42(suppl 16):S158-S171.

9. Aguirre-Zorzano LA, EstefaniaFresco R, Telletxea O, et al. Prevalence of peri-implant inflammatory disease in patients with a history of periodontal disease who receive supportive periodontal therapy. Clin Oral Impl Res. 2015;26:13381344.

10. Daubert DM, Weinstein BF, Bordin $S$, et al. Prevalence and predictive factors for peri-implant disease and implant failure: A cross-sectional analysis. J Periodontol. 2015:86:337-347.

11. Dalago HR, Schuldt Filho G, Rodrigues MA, et al. Risk indicators for peri-implantitis. A cross-sectional study with 916 implants. Clin Oral Implants Res. 2017:28:144-150.

12. Schwarz F, Becker K, Sahm N, et al. The prevalence of peri-implant diseases for two-piece implants with an internal tube-in-tube connection: A crosssectional analysis of 512 implants. Clin Oral Impl Res. 2017;28:24-28.

13. Konstantinidis IK, Kotsakis GA, Gerdes S, et al. Cross-sectional study on the prevalence and risk indicators of periimplant diseases. Eur J Oral Implantol. 2015:8:75-88.

14. Rokn A, Aslroosta H, Akbari S, et al. Prevalence of peri-implantitis in patients not participating in well-designed supportive periodontal treatments: A cross-sectional study. Clin Oral Implants Res. 2017:28:314-319.

15. Renvert S, Lindahl C, Persson GR. Occurrence of cases with peri-implant mucositis or peri-implantitis in a 21-26 years follow-up study. J Clin Periodontol. 2018; 45:233-240.

16. Roos-Jansåker AM, Lindahl C, Renvert $\mathrm{H}$, et al. Nine- to fourteen-year follow-up of implant treatment. Part II: Presence of peri-implant lesions. J Clin Periodontol. 2006;33:290-295.
17. Sanz M, Chapple IL. Clinical research on peri-implant diseases: Consensus report of working group 4. J Clin Periodontol. 2012;39:202-206.

18. Tomasi C, Derks J. Clinical research of peri-implant diseases-Quality of reporting, case definitions and methods to study incidence, prevalence and risk factors of peri-implant diseases. J Clin Periodontol. 2012;39(suppl 12): 207-223.

19. Zetterqvist L, Feldman S, Rotter B, et al. A prospective, multicenter, randomized-controlled 5-year study of hybrid and fully etched implants for the incidence of peri-implantitis. J Periodontol. 2010:81:493-501.

20. Koldsland OC, Scheie AA, Aass AM. Prevalence of peri-implantitis related to severity of the disease with different degrees of bone loss. J Periodontol. 2010; 81:231-238.

21. Derks J, Schaller D, Håkansson J, et al. Effectiveness of implant therapy analyzed in a Swedish population: Prevalence of peri-implantitis. J Dent Res. 2016;95:43-49.

22. Meijer HJ, Raghoebar GM, de Waal YC, et al. Incidence of peri-implant mucositis and peri-implantitis in edentulous patients with an implant-retained mandibular overdenture during a 10-year follow-up period. J Clin Periodontol. 2014:41:1178-1183.

23. Renvert S, Aghazadeh A, Hallström $\mathrm{H}$, et al. Factors related to periimplantitis-A retrospective study. Clin Oral Implants Res. 2014:25:522-529.

24. Costa FO, Takenaka-Martinez S, Cota LO, et al. Peri-implant disease in subjects with and without preventive maintenance: A 5-year follow-up. J Clin Periodontol. 2012:39:173-181.

25. Roccuzzo M, De Angelis N, Bonino $\mathrm{L}$, et al. Ten-year results of a three arms prospective cohort study on implants in periodontally compromised patients. Part 1: Implant loss and radiographic bone loss. Clin Oral Impl Res. 2010;21:490496.

26. Renvert S, Polyzois I. Risk indicators for peri-implant mucositis: A systematic literature review. J Clin Periodontol. 2015;42(suppl 16):S172-S186.

27. Renvert S, Lindahl C, Rutger Persson G. The incidence of periimplantitis for two different implant systems over a period of thirteen years. J Clin Periodontol. 2012;39:1191-1197.

28. Katafuchi M, Weinstein BF, Leroux $B G$, et al. Restoration contour is a risk indicator for peri-implantitis: A crosssectional radiographic analysis. J Clin Periodontol. 2018:45:225-232. 